\title{
Memory search processes for words and pictures in elementary school children
}

\author{
DENNIS A. McDERMOTT, MICHAEL E. YOUNG, ROBB M. GILFORD, and JAMES F. JUOLA \\ University of Kansas, Lawrence, Kansas 66045
}

\begin{abstract}
Children in the fourth and sixth grades searched memory sets of two, three, or four items for the presence of a given word or picture probe. The memory sets were all of one form on any trial, being either words or easily nameable pictures, and the probe form was varied to match or mismatch the form of the memory items. Subjects responded more rapidly when the probe form and memory set form matched, an effect that did not interact with the number of memory set items. Presumably, stimulus form effects are limited to encoding processes which precede comparisons between the probe and memory set items. The comparison process itself appears to be independent of the form in which the probe is presented.
\end{abstract}

The present study was designed to investigate stimulus encoding and memory comparison processes in children. Written words and their pictorial referents were used as stimuli in a Sternberg (1966) memory search task. The problem was to determine whether both encoding and comparison stages of the memory search process would be affected by the probe stimulus form. In a recent study using college students as subjects, Young and Juola (1977) demonstrated that stimulus encoding processes, but not subsequent comparison processes, were affected by the probe stimulus form. That is, the probes and memory set items were compared in some way that was apparently independent of whether or not their forms were the same. If similar results are obtained when children are used as subjects, it would indicate that they not only recognize stimulus equivalence at a conceptual level, but also can make comparisons between stimuli based on conceptual, rather than perceptual, information. If, however, the comparison process in children is based on perceptual aspects of the stimuli, then word and picture differences should exist at deeper levels of processing for children than for adults in short-term memory scanning.

\section{METHOD}

The subjects were 25 fourth-grade and 19 sixth-grade students selected randomly from class lists at Broken Arrow Elementary School, Lawrence, Kansas.

The stimuli consisted of slide transparencies containing single common typed nouns or photographs of easily nameable outline drawings selected from the set of items used by Young

This research was supported in part by Grant MH-24637-01 from the National Institute of Mental Health and Grant NIE-G$77-0010$ from the National Institute of Education to the fourth author. The project presented or reported herein was performed pursuant to a grant from the National Institute of Education, Department of Health, Education, and Welfare. However, the opinions expressed herein do not necessarily reflect the position or policy of the National Institute of Education, and no official endorsement by the National Institute of Education should be inferred. and Juola (1977). The stimuli included 72 pictures and 72 names of the same common objects. The words had a median frequency of occurrence in English of 9.7 occurrences per million words, as determined from the Carroll, Davies, and Richman (1971) counts for third-and fourth-grade reading material.

The subjects were run individually in three consecutive daily sessions. Each session included either 36 or 72 experimental trials preceded by 12 practice trials using materials similar to the experimental stimuli. All trials began with the serial presentation of a memory set of two, three, or four slides that were either all words or all pictures. These were presented at a fixed rate of $2 \mathrm{sec} / \mathrm{slide}$, and the end of the memory set was signaled by the presentation of a blank red slide for $2 \mathrm{sec}$. This slide was followed by the onset of the probe stimulus, which was the same as one of the memory set items on half the trials. The probe form was varied over the three sessions such that the probes were always words on one day, pictures on another, and mixed pictures and words on the third day. The fixed probe form sessions were 36 trials in length and the mixed probe form sessions were 72 trials long. The order of the sessions over days was randomly determined for each subject. Within each session, the three levels of memory set size (two, three, or four items), the memory set forms (words or pictures), and the two response types required (positive if the probe was the same as one of the memory set items regardless of form and negative otherwise) were varied factorially. The order in which the trials were presented was random. On positive trials, the serial position within the memory set of the item matching the probe was also randomly determined.

A Kodak Carousel projector was used to present the stimuli on a $25 \times 25 \mathrm{~cm}$ rear-projection screen, in front of which were mounted two telegraph keys $13 \mathrm{~cm}$ apart. Positive and negative responses were assigned to the two keys in a counterbalanced fashion, and the subjects were instructed to press the appropriate key as rapidly and accurately as possible in response to the probe stimulus.

\section{RESULTS}

The design was a factorial combination of the variables grade level (fourth or sixth), memory set size (two, three, or four items), memory set form (words or pictures), probe form expectancy (blocked or mixed), and response type (positive or negative). Separate analyses of variance were performed on the mean response times and the arc-sine-transformed error 
Table 1

Mean Response Times (in Milliseconds) and Error Proportions (in Parentheses) as Functions of Memory Set Size, Memory Set Form, and Response Type

\begin{tabular}{ccccc}
\hline \multirow{2}{*}{$\begin{array}{c}\text { Memory Set } \\
\text { Form }\end{array}$} & Response & \multicolumn{3}{c}{ Memory Set Size } \\
\hline \multirow{4}{*}{ Words } & \multirow{2}{c}{$\begin{array}{c}\text { No } \\
\end{array}$} & 968 & 1004 & 1082 \\
& & $(.053)$ & $(.052)$ & $(.065)$ \\
& & 960 & 1045 & 1045 \\
& & $(.111)$ & $(.088)$ & $(.091)$ \\
& & 964 & 1024 & 1064 \\
& & $(.082)$ & $(.070)$ & $(.079)$ \\
Pictures & No & 972 & 1013 & 1014 \\
& & $(.044)$ & $(.077)$ & $(.070)$ \\
& Yes & 946 & 1012 & 1013 \\
& & $(.085)$ & $(.092)$ & $(.113)$ \\
& & 959 & 1012 & 1014 \\
& & $(.065)$ & $(.085)$ & $(.092)$ \\
\hline
\end{tabular}

Table 2

Mean Response Times (in Milliseconds) and Error Proportions (in Parentheses) as Functions of Probe Form Expectancy (Blocked or Randomly Mixed), Probe Form, and Memory Set Form

\begin{tabular}{cccccc}
\hline & \multicolumn{2}{c}{ Blocked Probe Forms } & & \multicolumn{2}{c}{ Mixed Probe Forms } \\
\cline { 2 - 3 } \cline { 5 - 6 } $\begin{array}{c}\text { Memory Set } \\
\text { Form }\end{array}$ & \multicolumn{2}{c}{ Probe Form } & & \multicolumn{2}{c}{ Probe Form } \\
Words & $\mathrm{W}$ & $\mathrm{P}$ & $\mathrm{W}$ & $\mathrm{P}$ \\
\hline \multirow{2}{*}{ Pictures } & 957 & 1077 & 984 & 1044 \\
& $(.055)$ & $(.103)$ & $(.056)$ & $(.092)$ \\
& 1017 & 950 & 1027 & 987 \\
& $(.089)$ & $(.071)$ & $(.100)$ & $(.059)$ \\
\hline
\end{tabular}

proportions for each subject in all cells of the design.

In the response time analysis, significant main effects were found for memory set size $[F(2,86)=36.4$, $p<.001]$ and memory set form $[F(1,43)=7.85$, $\mathrm{p}<.01]$. The nature of these effects can be seen in Table 1, which presents the mean response times and error proportions as functions of memory set size, memory set form, and response type. In general, the responses were faster for picture memory sets than for words, and response times increased with set size. Although the set size effect was smaller for picture memory sets than for words, this difference was not significant, and the effect of set size was to add about $36 \mathrm{msec}$ to total response time for each additional memory set item.

Two significant interactions were found in the response time data: Probe Form by Memory Set Form $[F(1,42)=78.2, p<.001]$ and Probe Form by Memory Set Form by Prove Form Expectancy $[\mathrm{F}(1,42)=8.61$, $\mathrm{p}<.01]$. As shown in Table 2, responses were faster when memory sets and probes were of the same stimulus form than when the forms differed, and this effect was stronger in the blocked probe form sessions than in the mixed sessions. No other main effects or interactions were significant in the response time data.
A similar analysis of variance was performed on the arc-sine-transformed error data. The only significant main effect was response type $[F(1,42)=18.5$, $p<.001]$, with more errors made on positive trials than on negative trials. As might be expected from the response time data, fewer errors were made when the memory sets and the probe stimuli were of the same form than when they differed $[F(1,42)=19.1$, $\mathrm{p}<.001]$. Finally, the interaction of Probe Form Expectancy by Memory Set Size was significant $[F(2,84)=5.66, p<.01]$.

\section{DISCUSSION}

In general, the present results using fourth- and sixth-grade children replicated those obtained in a similar memory search experiment with adult subjects (Young \& Juola, 1977). That is, although responses were faster and more accurate when the memory set and probe were of the same stimulus form than when the forms differed, this effect was constant with respect to memory set size. An interpretation of this result in terms of the additive-factors logic of Sternberg (1969) would be that stimulus form and memory set size affect different processing stages in children's memory search. A model consistent with this interpretation would presume that the presentation of words or pictures as memory set items biases the stimulus encoding mechanism to favor either verbal or pictorial inputs. Thus, probe stimuli that match the memory items in form are encoded more rapidly, even if a probe of a different form is expected, as in the fixed probe form sessions. Once the encoding process is complete, however, the comparison of probes and memory items is unaffected by the form of the stimuli. If we disallow the unlikely possibility that perceptual codes of pictures and words are compared at the same rate in short-term memory, we must assume that this comparison is based on more abstract, conceptual representations of the stimuli. Several experiments reported by Maisto and Baumeister (1975) provide justification for the use of the additive-factors logic in memory search tasks involving children; they also found that manipulations of probe stimulus form (intact vs degraded) affected encoding but not the comparison stage of processing.

In summary, children as young as those in our sample of fourth graders recognize conceptual equivalence between pictures and their names. This recognition of equivalence enables comparisons between encoded stimuli and remembered items to be based on conceptual rather than on perceptual codes. Although comparisons made at a deeper level of processing necessarily involve more complex stimulus encoding operations, these are apparently compensated for by more efficient processing of conceptual than perceptual information in memory.

\section{REFERENCES}

Carroll, J. B., Davies, P., \& Richman, B. The American Heritage word frequency book. New York: Houghton Mifflin, 1971.

Maisto, A. A., \& Baumeister, A. A. A developmental study of choice reaction time: The effect of two forms of stimulus degradation on encoding. Journal of Experimental Child Psychology, 1975, 20, 456-463.

Sternderg, S. High-speed scanning in human memory. Science, $1966,153,652-654$.

STERnBerg, S. Memory scanning: Mental processes revealed by reaction-time experiments. American Scientist, 1969, 57, 421-457.

Young, M., \& Juola, J. Stimulus-form effects in recognition memory. Memory \& Cognition, 1977, 5, 131-138.

(Received for publication March 9, 1977.) 